\title{
Dynamics of soil water content during depletion cycles in peach orchards in a semiarid region
}

\author{
Cristian Paltineanu ${ }^{1 *}$, Leinar Septar ${ }^{1}$, and Cristina Moale ${ }^{1}$
}

Due to the competition for water resources, increasing efforts are done in order to use more efficiently irrigation water in agriculture. The purpose of this paper is to find out daily soil water content (SWC) dynamics during depletion cycles in order to emphasize its pattern and compare daylight $v s$. night (dark) and morning $v s$. afternoon SWC dynamics in an irrigated peach (Prunus persica [L.] Batsch) orchard under various soil water regimes. To do this, four depletion cycles were studied after irrigation application in two treatments: fully irrigated (T1) and water stressed (T2), in a semiarid region of Romania. Soil water potential was continuously measured with Watermark resistance blocks. Daylight soil water discharge (SWD) is higher than night SWD (1.87 ratio in T1 and 1.50 in T2) mainly due to solar radiation (Rs), higher vapor pressure deficit (VPD), and wind speed (U), with crop transpiration and crop water uptake being higher during daylight vs. nighttime. SWD during 14:00-20:00 h is greater than 08:00-14:00 h due to higher afternoon values of air temperature (T), VPD, and U. The results help understand better the relations between the daily dynamics of SWC and Rs, T, VPD, and $\mathrm{U}$, and could be utilized by fruit growers to improve water management and conservation in semiarid regions with similar environmental conditions.

Key words: Climatic factors, irrigation, Prunus persica, soil water discharge.

\section{INTRODUCTION}

Due to the competition for water resources, increasing efforts are done in order to use more efficiently irrigation water in agriculture, specifically in the context of future global changes. According to Ruiz-Sanchez et al. (2010), when the water supply is continuous it is possible to apply one of the following strategies: regulated deficit irrigation, RDI (Chalmers et al., 1981); partial rootzone drying, PRD (Dry et al., 1996); or sustained deficit irrigation, SDI (Goldhamer et al., 2006), the latter based on distributing the water deficit uniformly over the whole crop cycle to avoid the occurrence of severe water stress at any particular moment, which might have unfortunate results. Soil water content (SWC) dynamics depends on both daytime and nighttime crop evapotranspiration. In order to measure nighttime crop transpiration, various methods have been used: gas exchange measurements of individual leaves, whole-plant sap flow, and field scale lysimeter determinations (Benyon, 1999; Snyder et al., 2003; Bucci et al., 2004; Daley and Phillips, 2006; Caird et al., 2007). "Nevertheless, there is broad

${ }^{1}$ Research Station for Fruit Growing Constanta, commune Valu lui Traian, Pepinierei str., nr 1, County Constanta, Romania. "Corresponding author (cristian_paltineanu@yahoo.com).

Received: 29 March 2013.

Accepted: 1 August 2013.

doi:10.4067/S0718-58392013000400011 agreement among the methods and scales that stomata of many species remain partially open during the night, and the magnitude of water loss occurring during the night depends on both night leaf conductance for water and vapor pressure difference between leaves and the air, as well as canopy structure and atmospheric mixing" (Caird et al., 2007).

Some authors have reported that nighttime stomatal opening is unexpected because $\mathrm{C}$ gain does not occur and the need to cool leaves is reduced or absent; most species have the ability to close stomata more than is commonly observed at night in response to water stress. Other authors emphasize the potential physiological benefits due to nighttime transpiration for the plants, such as a better nutrient acquisition and an increased total daily mass flow of water to roots, which is important for supply of $\mathrm{NO}_{3}{ }^{-}$ (Nye and Tinker, 1977; McDonald et al., 2002, Snyder et al., 2003). Hydrometeorological models based on current and future climates may need to modify algorithms of plant water use, particularly if this phenomenon of nighttime water loss is widespread in warm, dry environments, such as the warm desert, with high nighttime vapor pressure deficits (Snyder et al., 2003). Other aspects on stomatal conductance were also reported by Correia et al. (1997) and Tardieu and Davies (1992), who stated that for the same abscisic acid (ABA) concentration in the xylem sap of field-grown trees, leaf conductance was lower in the afternoon than in the morning. 
Other recent investigations based on sap flow measurements and carried out in orchards (sweet cherry) revealed new findings on tree transpiration during daytime and nighttime too (Juhász, 2012).

Crop transpiration and evaporation consistently influence the dynamics of SWC, which also depends on its initial values, either in fully irrigated orchards or in water stressed plantations. However, the separation between daytime and nighttime SWC related to climate features is not fully clarified.

The objective of this paper was to find out daily SWC variation during depletion cycles in order to emphasize the pattern of daylight $v s$. night (dark) SWC dynamics and the pattern of morning $v s$. afternoon one, in an irrigated peach orchard under various soil water stress conditions, in a Chernozem of Romania.

\section{MATERIALS AND METHODS}

\section{Soil and climate conditions}

The largest semi-arid area of Romania is located in the southeastern part of the country, i.e. Dobrogea region $\left(43^{\circ} 42^{\prime}-45^{\circ} 20^{\prime} \mathrm{N}, 27^{\circ} 50^{\prime}-29^{\circ} 41^{\prime}\right.$ E). The Prunus persica (L.) Batsch orchard under study is located in Valu lui Traian, district Constanta, in the eastern part of Dobrogea, Romania.

The climatic data: solar radiation (Rs), air temperature (T), relative air humidity $(\mathrm{RH})$, wind speed at the height of $2 \mathrm{~m}(\mathrm{U})$, precipitation $(\mathrm{P})$, and Penman-Monteith $\mathrm{ET}_{0}$ $\left(\mathrm{PM}-\mathrm{ET}_{0}\right)$ have been recorded by an automatic weather station (WatchDog Weather Station 2000, Spectrum Technologies, Aurora, Illinois, USA) by a 30-min step and averaged for 1-h intervals. The station possessing mowed sod as reference cover is located at a distance of about $100 \mathrm{~m}$ from the experimental plot. These data have been periodically transferred by wire to a laptop and processed as diurnal means and used in calculations. The study was performed in the 2011 growing season, and the measurements were taken during June-August. PM-ET 0 was calculated using the combined equation (Allen et al., 1998) based on daily climate data and grass reference. The climate conditions at the experimental site are characterized by a mean annual temperature of $10.7^{\circ} \mathrm{C}$ and a mean annual precipitation of $409 \mathrm{~mm}$ (Paltineanu et al., 2007), not uniformly distributed across the year; for the whole year PM-ET 0 totalizes $778 \mathrm{~mm}$, with an average of 122,133 , and $118 \mathrm{~mm} \mathrm{mo}^{-1}$ during June, July and August, respectively. During the irrigation period (months VI-VIII), the useful-in-agriculture rainfall $(>3$ $\mathrm{mm}$ ) was low during the experiment, totaling $95.2 \mathrm{~mm}$,

Table 1. Rainfall amount of agricultural importance $(>3 \mathrm{~mm})$ during the irrigation period (June-August) at Valu lui Traian, Constanta district, Romania.

\begin{tabular}{llllllllll}
\hline DOY & 161 & 163 & 183 & 185 & 203 & 208 & 212 & 225 & Total \\
\hline Rainfall, mm & 9.0 & 4.0 & 10.1 & 7.1 & 25.6 & 11.5 & 18.1 & 9.8 & 95.2
\end{tabular}

DOY: day of year. from day of year (DOY) 161 to 263 (Table 1), with an average rain event of about $12 \mathrm{~mm}$.

The soil is a Calcaro-Calcic Chernozem (World Reference Base for Soil Resources, 2006) or Entic Haplustolls (Soil Survey Staff, 1999) with a loamy texture and alkaline $\mathrm{pH}$ in topsoil, which has a good soil structure and fertility. There is proper soil homogeneity for large areas in this region. Land slope is between 2.0 and $2.5 \%$ and soil bulk density ranges from 1.18 to $1.25 \mathrm{~g} \mathrm{~cm}^{-3}$. The main soil water content indexes - permanent wilting point (WP), field capacity (FC), critical depletion level or management allowed deficit (MAD), and total soil water capacity (TC) on the soil profile down to $1 \mathrm{~m}$ depth - were previously determined at the studied site. For this depth, the values of the above indexes $\left(\% \mathrm{~cm}^{3} \mathrm{~cm}^{-3}\right)$ are: WP is 12.1; FC is 29.9, while MAD is 21.0 and TC is 55.2. There is a large range between $\mathrm{FC}$ and $\mathrm{TC}$ where water can infiltrate without causing waterlogging or air deficits.

\section{Experimental design and irrigation application}

The Southland cultivar was grafted on franc rootstock, and the 16-yr old fruit trees were planted in a $4 \mathrm{~m} \times 3$ $\mathrm{m}$ scheme with North-South row orientation. The average tree height is $2.5 \mathrm{~m}$ and tree canopy shape is a palmette. The soil management system is represented by clean cultivation (bare soil) both between tree rows and in the row.

The experiment design was based on the single-factor design with two treatments: T1 -non-stressed, fully irrigated according to the irrigation needs calculated by help of PM-ET $\mathrm{PT}_{0}$ multiplied by $\mathrm{Kc}$ (Kc from Allen et al., 1998), as previously described and confirmed for the region by Paltineanu et al. (2007), and with Kc values for the period investigated of 0.76 in June, 0.89 in July and 0.88 in August (Paltineanu et al., 2007), with irrigation application carried out when SWC was about to reach the mid-interval between FC and WP, i.e. MAD, and T2- a water stressed treatment irrigated with half the amount of water in T1 and almost simultaneously applied. Each plot consisted of three adjacent fruit tree rows, with the central row containing five trees for various measurements and observations. The treatments were separated by an isolating distance of $40 \mathrm{~m}$ (Figure 1).

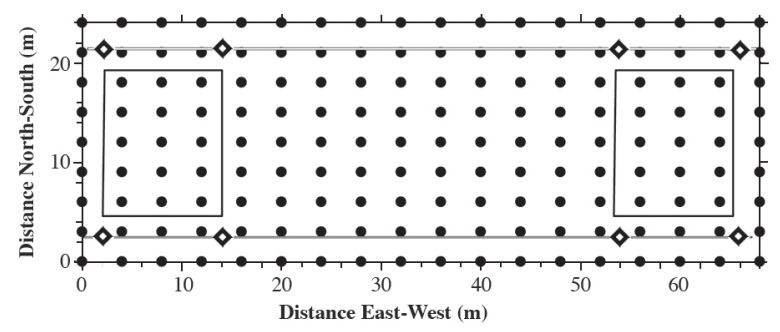

Figure 1. The experimental design used in the two treatments, fully irrigated T1 (left) and water stressed T2 (right), bordered by four sprinklers (rhombs) each and containing 15 fruit trees (black circles); horizontal lines represent 18 -m spaced irrigation pipes. 
Sprinkler irrigation has been applied using a $12 \mathrm{~m} \times$ $18 \mathrm{~m}$ grid scheme, a pressure of about $0.3 \mathrm{MPa}$ at the sprinkler nozzle, which is $7 \mathrm{~mm}$ in diameter, giving a 7.4 $\mathrm{mm} \mathrm{h}^{-1}$ application rate as measured in catch cans placed in a $1 \mathrm{~m}$ grid. Four $60 \mathrm{~mm}$ irrigation applications were performed in T1 during June and July (DOY 154, 172, 187 and 207, Figure 2) totaling $240 \mathrm{~mm}$, while in T2 the $30 \mathrm{~mm}$ irrigation amounts totaled $120 \mathrm{~mm}$. After harvest (mid August), the trees were no longer irrigated.

\section{Soil water content measurements}

Four depletion cycles were investigated after irrigation application in the reference plots to notice the SWC variation, i.e., crop evapotranspiration and deep percolation combined, during both light period and dark (night) period, in both $\mathrm{T} 1$ and $\mathrm{T} 2$. Each depletion cycle during summer time has been considered as a replicate for the variation of SWC.

Soil water potential was measured continuously with Watermark resistance blocks (6450 Watermark Soil Moisture Sensor, Spectrum Technologies) installed in two replicates for each fruit tree at four depths: 20,40,60, and $80 \mathrm{~cm}$ at a $1-\mathrm{m}$ horizontal distance from the central tree trunk in the middle row. One set of sensors was installed between fruit trees on the row and the other one at right angle between the rows. Data were recorded by WatchDog dataloggers (WatchDog Model 1650 Data Logger,
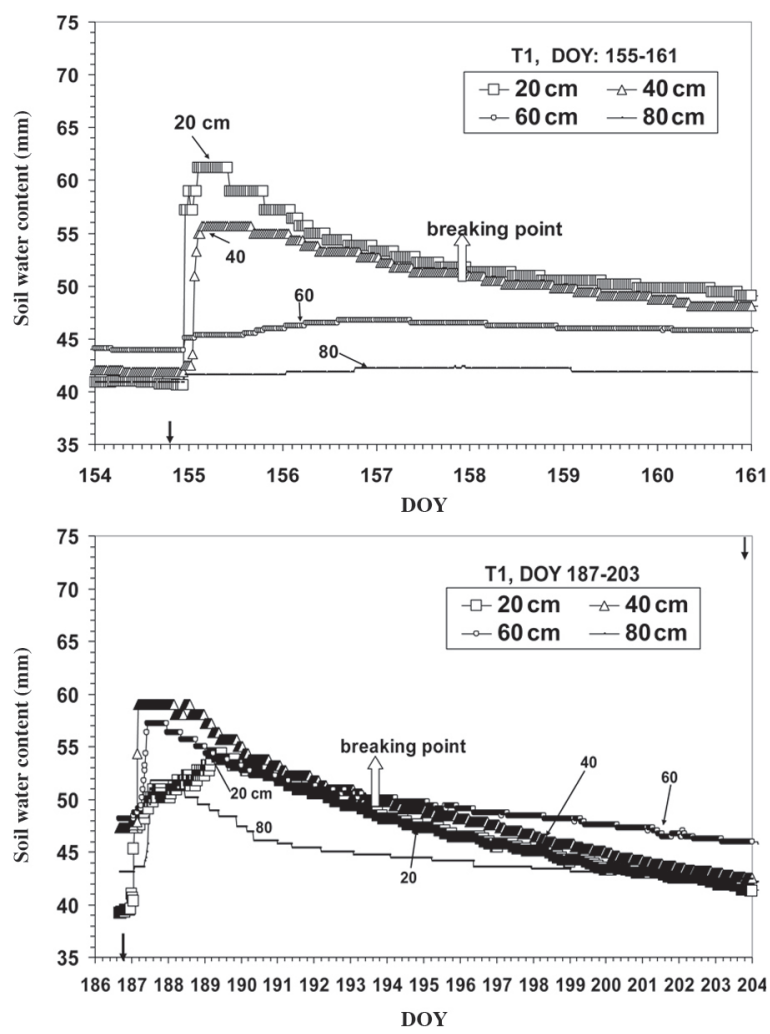

Spectrum Technologies) and downloaded periodically by a laptop. "The relationship between soil water potential measured with the Watermark sensors and SWC measured gravimetrically was previously determined from field data only when drying, to minimize the hysteresis" (Paltineanu et al., 2011); it was then applied to the soil water potential readings during the experiment in order to estimate SWC values, which were averaged over the normal active rooting depth of $80 \mathrm{~cm}$ as found previously in the region for mature peach fruit trees (Indreias, 1997). Soil water discharge (SWD) was calculated on a daily basis after transforming SWC expressed as volumetric units into $\mathrm{mm}$ of water, and then subtracting these values from each other for each period considered.

\section{RESULTS AND DISCUSSIONS}

\section{Pattern of SWC at various depths during the depletion cycles}

As a general rule, the upper soil horizons got wet earlier than the deeper ones, emphasizing a relatively normal infiltration pattern (Figure 2). One may note some breaking points about 3-8 d after irrigation application in the non-stressed treatment, depending on the magnitude of water stored in soil, and these SWC values correspond to a soil water matrix potential value of about 20-30 $\mathrm{kPa}$ representing around $65-77 \%$ of the available SWC
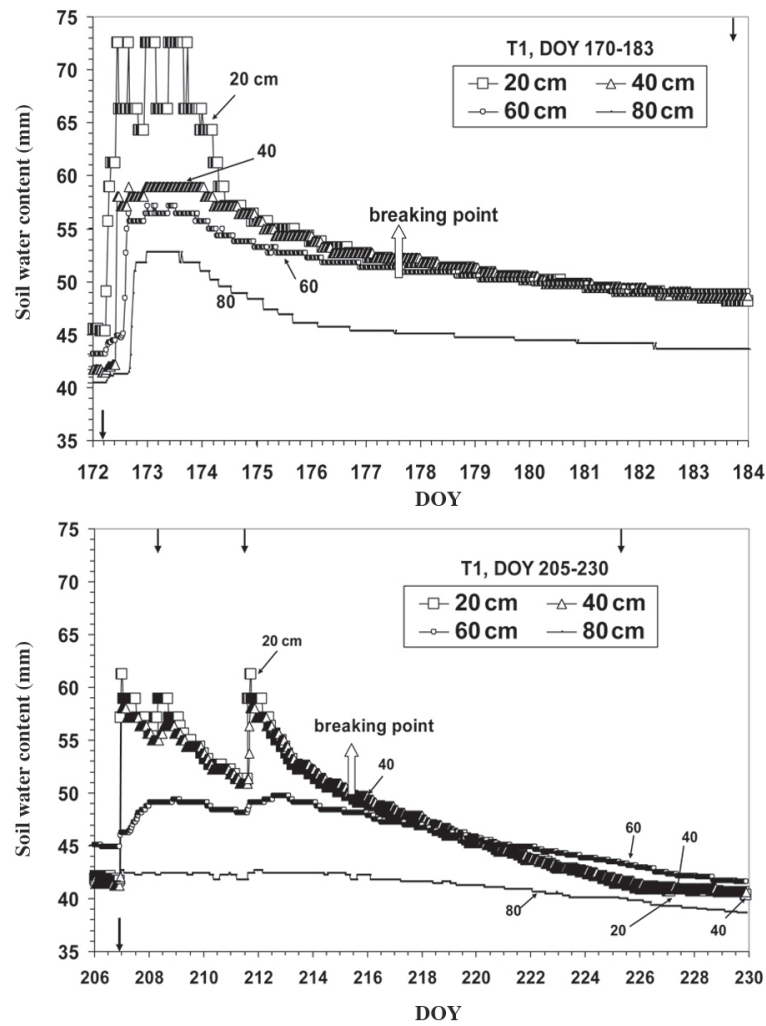

Figure 2. Soil water content in the four depletion cycles in the non-stressed treatment (T1) for peach, at four depths in the soil profile after irrigation application; lower arrows show the moments of irrigation applications and upper arrows depict the days of useful rainfall ( $>3$ mm). DOY: day of year. 
(Paltineanu et al., 2011). However, soil water processes (evaporation, transpiration and deep percolation, no runoff) determine changes in SWC, but they cannot be separated this way and one cannot state that the above breaking points represent the onset of water stress for peach. In addition to evaporation, the main useful soil water depletion process, i.e. crop transpiration, also depends on the distribution of the root system within the soil and plant water uptake as well. For this cultivarrootstock combination, a previous study performed in the area has shown that the most active fruit tree roots ( $<1 \mathrm{~mm}$ diameter) reach about $90 \%$ of the total number of roots, and they are distributed essentially between 10 and $70 \mathrm{~cm}$ soil depth, with a peak in the $20-40 \mathrm{~cm}$ depth (Indreias, 1997). The same author has also shown that more than $85 \%$ of the whole rooting system is within the first $80 \mathrm{~cm}$ depth in irrigated soils. Our data on soil water depletion (Figure 2) are consistent with the tree rooting and water uptake pattern described above.

\section{Pattern of light vs. night SWC dynamics}

In order to investigate when SWC dynamics is more intense and to separate the nighttime (dark) SWC and the daylight SWC variations, the daily distribution of Rs, T, VPD, RH, and U was also used to compare some SWD ratios. Figure 3 shows the mean values of the climate characteristics during the average day, respectively, in those 3-mo. Proper time symmetry and a clear separation of the daylight/night equal periods in the case of Rs (Table 2) can be noticed, and $\mathrm{T}$ is better characterized by the statistics shown in the same table, while VPD and $\mathrm{U}$ are described in Table 3 . In order to have two equal parts of the day, the 08:00 and 20:00 $\mathrm{h}$ were selected as margins, because the Rs means and standard deviations calculated during these two intervals reveal relative homogeneous groups of values. For instance, the means ranged between 45.9 and $52.6 \mathrm{MJ} \mathrm{m}^{-2} \mathrm{~s}^{-1}$ on daylight and between 0.5 and $1.6 \mathrm{MJ} \mathrm{m}^{-2} \mathrm{~s}^{-1}$ at night. In investigating SWC dynamics, the daylight part was further split into

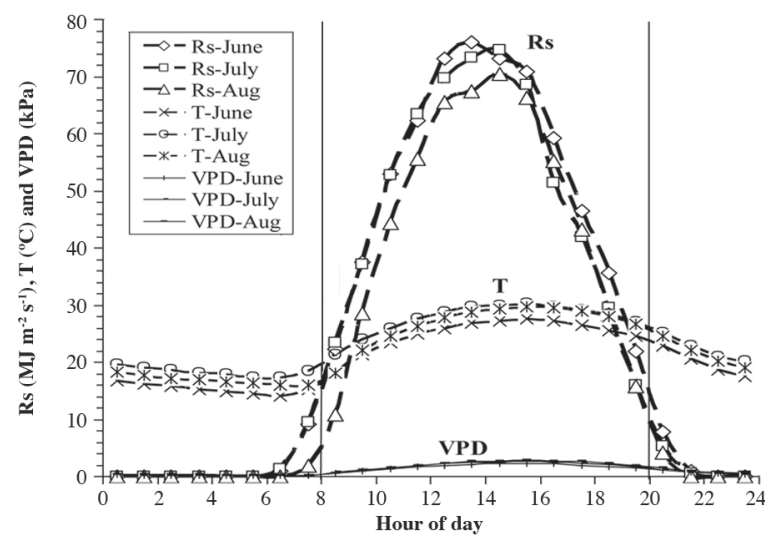

Figure 3. Average values of solar radiation (Rs), air temperature (T) and vapor pressure deficit (VPD) during the day in the months investigated (June-Aug). two equal parts, from 08:00 to 14:00 h, and from 14:00 to $20: 00 \mathrm{~h}$, respectively, and all the Rs statistics were somehow similar, with means between 45 and $54 \mathrm{MJ} \mathrm{m}^{-2}$ $\mathrm{s}^{-1}$, the first period characterized by higher means. Air temperature shows a different kind of time distribution. There were clear differences between daylight and dark periods, as expected, with similar standard deviation. Unlike the Rs distribution, the two parts of the daylight period, i.e. 08:00-14:00 $\mathrm{h}$ and 14:00-20:00 h, present inverse differences, of $3-4{ }^{\circ} \mathrm{C}$, and the latter is warmer.

VPD has values describing a drier period during daylight $v s$. night in all summer months studied, with August being the driest (Table 3); during daylight, VPD varies from 1.73 to $2.11 \mathrm{kPa}$, while during night it ranges from 0.36 to $0.52 \mathrm{kPa}$. Within the daylight, the $14-20 \mathrm{~h}$ period was drier than the 08:00-14:00 h, with the following VPD values: 2.0 to $2.55 \mathrm{kPa} v s .1 .44$ to $1.68 \mathrm{kPa}$. U values were much higher during daylight $\left(0.23-0.45 \mathrm{~m} \mathrm{~s}^{-1}\right) \mathrm{vs}$. night (0.04-0.06 $\left.\mathrm{m} \mathrm{s}^{-1}\right)$, and during the afternoon $(0.26$ $\left.0.51 \mathrm{~m} \mathrm{~s}^{-1}\right) v s$. the morning $\left(0.19-0.40 \mathrm{~m} \mathrm{~s}^{-1}\right)$.

The ratio between the daily SWD and PM-ET 0 (only for cycle 1, Figure 4) makes sense only for the non-stressed treatment $\mathrm{T} 1$, being compared to the Kc coefficient from the method of Allen et al. (1998) and published as regionalized Kc values for this region by Paltineanu et al. (2007). During three out of four depletion cycles investigated, this ratio was lower than $\mathrm{Kc}$, and this was significant in three out of the four cycles and (Table 4). The significance test has been carried out using Student's t-test (Iosifescu et al., 1985) to find out if the compared means

Table 2. Solar radiation (Rs) and air temperature (T) depicted as $\mathrm{Rs} / \mathrm{T}$ ratios for the two parts of the day: daylight (08:00-20:00 h) and dark (20:00-08:00 h), as well as for the two parts of the daylight: morning (08:00-14:00 h) and afternoon (14:00-20:00 h), as means and standard deviation $\left(\mathrm{MJ} \mathrm{m}^{-2} \mathrm{~s}^{-1}\right.$ and ${ }^{\circ} \mathrm{C}$, respectively) for the 3-mo investigated.

\begin{tabular}{llccc}
\hline Hours of day & Statistics/Month & June & July & August \\
\hline Daylight & Mean & $52.6 / 25.0$ & $50.1 / 27.7$ & $45.9 / 26.7$ \\
(08:00-20:00 h) & Standard deviation & $19.7 / 2.8$ & $20.5 / 2.7$ & $20.9 / 3.5$ \\
Dark & Mean & $1.6 / 16.8$ & $1.4 / 19.6$ & $0.5 / 18.4$ \\
(20:00-08:00 h) & Standard deviation & $3.2 / 2.7$ & $3.0 / 2.3$ & $1.3 / 2.7$ \\
Morning & Mean & $54.0 / 23.5$ & $53.3 / 26.2$ & $45.4 / 24.6$ \\
(08:00-14:00 h) & Standard deviation & $21.0 / 3.2$ & $19.6 / 3.1$ & $22.2 / 4.0$ \\
Afternoon & Mean & $51.2 / 26.4$ & $47.0 / 29.1$ & $46.5 / 28.7$ \\
(14:00-20:00 h) & Standard deviation & $20.3 / 1.1$ & $22.6 / 1.2$ & $21.6 / 1.2$ \\
\hline
\end{tabular}

Table 3. Vapor pressure deficit (VPD, kPa) and wind speed at 2-m height $\left(\mathrm{U}, \mathrm{m} \mathrm{s}^{-1}\right)$ depicted as $\mathrm{VDP} / \mathrm{U}$ ratios for the two parts of the day: daylight (08:00-20:00 h) and dark (20:00-08:00 h), as well as for morning (08:00-14:00 h) and afternoon (14:00-20:00 h), as means and standard deviation ( $\mathrm{kPa}$ and $\mathrm{m} \mathrm{s}^{-1}$, respectively) for the 3-mo investigated.

\begin{tabular}{llccc}
\hline Hours of day & Statistics/Month & June & July & August \\
\hline Daylight & Mean & $1.73 / 0.45$ & $1.94 / 0.23$ & $2.11 / 0.32$ \\
(08:00-20:00 h) & Standard deviation & $0.54 / 0.16$ & $0.59 / 0.06$ & $0.73 / 0.11$ \\
Dark & Mean & $0.36 / 0.05$ & $0.39 / 0.04$ & $0.52 / 0.06$ \\
$(20: 00-08: 00 \mathrm{~h})$ & Standard deviation & $0.30 / 0.04$ & $0.30 / 0.02$ & $0.58 / 0.04$ \\
Morning & Mean & $1.44 / 0.40$ & $1.64 / 0.19$ & $1.68 / 0.27$ \\
(08:00-14:00 h) & Standard deviation & $0.59 / 0.17$ & $0.66 / 0.06$ & $0.79 / 0.10$ \\
Afternoon & Mean & $2.01 / 0.51$ & $2.24 / 0.26$ & $2.55 / 0.37$ \\
$(14: 00-20: 00 \mathrm{~h})$ & Standard deviation & $0.30 / 0.13$ & $0.34 / 0.05$ & $0.33 / 0.09$ \\
\hline
\end{tabular}


are significantly different or not. The number of data pairs was different in the four depletion cycles investigated: 6, 9, 15, and 13, respectively. Thus, t-test for the ratios: (light/ dark) SWD, hours (14:00-20:00/08:00-14:00) SWD and daily (SWD/PM-ET ${ }_{0}$ ) had the following values for T1 in the four cycles: $0.13,0.42,2.58$ for the first cycle, 0.92 , $0.74,0.49$ for the second, $1.54,0.51,5.39$ for the third, and $1.42,0.49,2.27$ for the fourth, respectively.

So, for June daily (SWD/PM-ET ${ }_{0}$ ) ratio was $0.61 \mathrm{vs}$. kc $=0.76$, with the difference being significant for the first depletion cycle, and $0.78 \mathrm{vs} . \mathrm{kc}=0.76$ for the second, non-significant, while for July this was $0.53 \mathrm{vs} . \mathrm{kc}=0.89$, with a highly significant difference for the third cycle, and $0.69 v s . \mathrm{kc}=0.88$, significant, for the fourth cycle mainly occurred in August. Under fully irrigated conditions, even if these values were expected to be equal, the lower values of this ratio $v s$. Kc could be explained not only by the spatial variability of the soil and orchard, but also by the relatively old age of the trees (16 yr), which might have diminished their water uptake potential; however, this hypothesis remains to be proved concerning Kc.

Soil water discharge (SWD) was thus separated according to the day parts explained above. Figure 4 shows daily values of T1 SWD and its components,

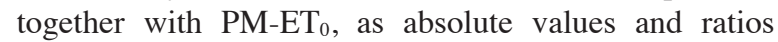
between some of these components. These ratios are: 1) SWD from 14:00 to 20:00 $\mathrm{h}$ divided to SWD recorded between 08:00 and 14:00 h; 2) daylight SWD divided to dark SWD and 3) SWD for the whole day per PM$\mathrm{ET}_{0}$. During the four depletion cycles, whole day SWD decreased in the first 1-2 d from irrigation ceasing, from about $7 \mathrm{~mm} \mathrm{~d}^{-1}$ to almost $2 \mathrm{~mm} \mathrm{~d}^{-1}$. SWD is controlled by soil physical properties like unsaturated hydraulic conductivity, soil water potential, hydraulic gradients for

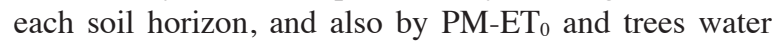
uptake (transpiration).
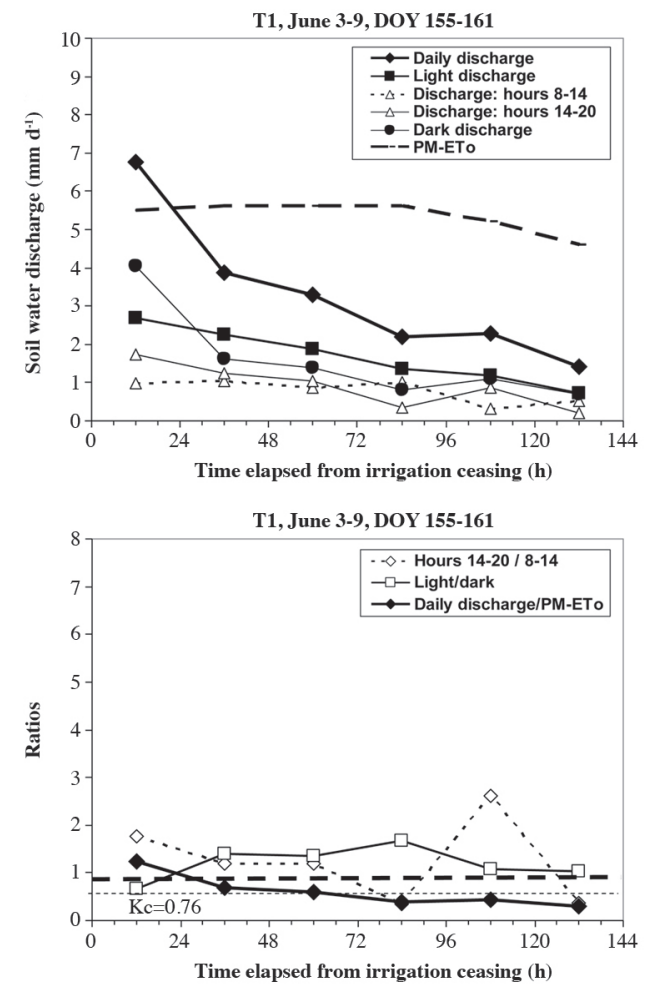

Figure 4. The daily values of soil water discharge (SWD) on the 0-80 cm depth and its components during depletion cycle 1 in $\mathrm{T} 1$ and Penman-Monteith $\mathrm{ET}_{0}\left(\mathbf{P M}-\mathrm{ET}_{0}\right)$ in the left side, and ratios between these components on the right side: 1) SWD from 14:00 to 20:00 h per SWD from 08:00 and 14:00 $\mathrm{h}, 2$ ) SWD between daylight and dark, 3) SWD for the whole day per PM-ET ${ }_{0}$. DOY: day of year.

Table 4. Statistics of the soil water discharge (SWD, $\mathrm{mm} \mathrm{d}^{-1}$ ) [mean, standard deviation - SD and t-test significance (***highly, **distinctly, and *significant) for the means of: daily SWD vs. Penman-Monteith ET (PM-ET $_{0}, \mathrm{~mm} \mathrm{~d}^{-1}$ ), light SWD vs. dark SWD, 14:00-20:00 h SWD vs. 08:00-14:00 h SWD], for the four depletion cycles after irrigation application in the well-watered treatment $\mathrm{T} 1$ and stressed treatment $\mathrm{T} 2$ alike.

\begin{tabular}{|c|c|c|c|c|c|c|c|c|c|}
\hline \multirow[b]{2}{*}{$\begin{array}{l}\text { Depletion cycle } \\
\text { and its statistics }\end{array}$} & \multicolumn{5}{|c|}{ Daily soil water discharge (SWD, $\mathrm{mm}$ ) } & \multirow[b]{2}{*}{${\mathrm{PM}-\mathrm{ET}_{0}}$} & \multicolumn{3}{|c|}{ Ratios between SWD types } \\
\hline & Daily & Light & 08:00-14:00 h & 14:00-20:00 h & Dark & & Light/dark & $\begin{array}{c}14: 00- \\
20: 00 / 08: 00- \\
14: 00 \mathrm{~h}\end{array}$ & Daily/PM-ET 0 \\
\hline & \multicolumn{9}{|c|}{$\mathrm{T} 1$} \\
\hline Cycle 1 Mean & 3.30 & 1.69 & 0.79 & 0.90 & 1.61 & 5.35 & 1.20 & 1.25 & $0.61 *$ \\
\hline Cycle 1 SD & 1.91 & 0.73 & 0.29 & 0.57 & 1.25 & 0.40 & 0.35 & 0.86 & 0.33 \\
\hline Cycle 2 Mean & 3.42 & 2.07 & 1.19 & 0.88 & 1.35 & 3.98 & 2.17 & 1.02 & 0.78 \\
\hline Cycle 2 SD & 3.24 & 1.59 & 1.06 & 0.64 & 1.72 & 1.07 & 0.95 & 0.76 & 0.54 \\
\hline Cycle 3 Mean & 2.78 & 1.66 & 0.78 & 0.88 & 1.13 & 5.27 & 1.88 & 1.46 & $0.53 * * *$ \\
\hline Cycle 3 SD & 1.64 & 1.01 & 0.54 & 0.57 & 0.85 & 0.71 & 1.67 & 1.07 & 0.28 \\
\hline Cycle 4 Mean & 2.99 & 1.78 & 0.83 & 0.95 & 1.22 & 4.23 & 2.22 & 1.29 & $0.69 *$ \\
\hline Cycle 4 SD & 1.77 & 1.13 & 0.57 & 0.64 & 0.87 & 0.85 & 2.31 & 0.91 & 0.30 \\
\hline \multirow[t]{2}{*}{ General average } & 3.12 & 1.80 & 0.90 & 0.90 & 1.33 & 4.71 & 1.87 & 1.25 & 0.65 \\
\hline & \multicolumn{9}{|c|}{$\mathrm{T} 2$} \\
\hline Cycle 1 Mean & 2.24 & 1.24 & 0.48 & 0.75 & 1.06 & 5.03 & 1.29 & 2.27 & $0.45^{* *}$ \\
\hline Cycle 1 SD & 0.60 & 0.41 & 0.30 & 0.29 & 0.20 & 0.46 & 0.47 & 1.94 & 0.14 \\
\hline Cycle 2 Mean & 3.74 & 3.00 & 4.98 & 3.45 & 2.48 & 4.24 & 3.40 & 8.64 & 2.89 \\
\hline Cycle 2 SD & 7.04 & 9.07 & 16.95 & 10.96 & 5.16 & 2.13 & 10.38 & 24.26 & 8.82 \\
\hline Cycle 3 Mean & 1.50 & 0.47 & 0.20 & 0.27 & 1.22 & 5.27 & $0.49 * * *$ & 2.45 & $0.30 * * *$ \\
\hline Cycle 3 SD & 0.57 & 0.27 & 0.27 & 0.15 & 0.52 & 0.71 & 0.37 & 1.58 & 0.16 \\
\hline Cycle 4 Mean & 3.63 & 1.66 & 0.70 & 0.97 & 1.97 & 4.23 & 0.81 & 2.00 & 0.87 \\
\hline Cycle 4 SD & 2.20 & 1.54 & 0.72 & 0.89 & 0.80 & 0.85 & 0.53 & 2.12 & 0.43 \\
\hline General average & 2.78 & 1.59 & 1.59 & 1.36 & 1.68 & 4.69 & 1.50 & 3.84 & 1.13 \\
\hline
\end{tabular}


The components of whole day SWD: daylight and dark SWD, and the components of daylight SWD, i.e. 08:00 to 14:00 $\mathrm{h}$ and 14:00 to 20:00 $\mathrm{h}$ SWD, are best seen as ratios on the right hand side of Figure 4. One can see that these ratios are not equal, the daylight SWD is higher than dark SWD, and the hours 14 to 20 SWD is also bigger than the 08:00 to 14:00 $\mathrm{h}$ SWD. At the same time, the whole day SWD is lower than PM-ET 0 . However, the dynamics of these ratios are quantified and tested, and Table 4 shows the statistics regarding SWD over the periods studied here for T1 and T2. Thus, the ratio between light SWD and dark SWD is always higher than 1 , ranging from 1.20 to 2.22 in $\mathrm{T} 1$, with an average of 1.87 , and from 0.49 to 3.40 in T2, with an average of 1.50 , but the coefficient of variation is pretty high; consequently, t-test applied here is not significant for the difference between these two means. Even if $\mathrm{PM}-\mathrm{ET}_{0}$ is in a causal relationship $v s$. net radiation $(\mathrm{Rn}), \mathrm{T}, \mathrm{RH}$, and $\mathrm{U}$, we investigated the coefficients of determination between these variables (with Rs that was measured, instead of $\mathrm{Rn}$ ), and the following relationship was obtained:

$$
\mathrm{ET}_{0}=0.1617 \times \mathrm{Rs}+0.6518
$$

Thus, the magnitude of the above ratio seems to be mainly influenced by Rs. This relationship emphasizes the strength between reference PM-ET 0 (implicitly crop evapotranspiration, Allen et al., 1998) and Rs during daylight for the period investigated, with a high coefficient of determination $\left(\mathrm{R}^{2}=0.88 * * *\right.$, highly significant, $\left.\mathrm{n}=92\right)$. Due to the narrow range of the other climatic elements ( $\mathrm{T}, \mathrm{RH}$, and $\mathrm{U}$ ) for the studied period, the relationships between them and PM-ET ${ }_{0}$ were not significant. However,

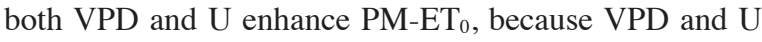
are higher during daylight $v$ s. night (Table 3 ).

\section{DISCUSSION}

Due to the high leaf stomatal conductance for water and crop cooling requirements during daylight, transpiration and soil water uptake by the tree roots are much higher now vs. nighttime, and the general average of this ratio is $1.87 \mathrm{in} \mathrm{T1}$ and 1.50 in T2, non-significant in either of them.

Most of SWD is probable due to the effect of crop transpiration, "as in mature peach orchards soil evaporation is usually small, varying from around $10 \%$ of crop ET" (Paço et al., 2004) to 18\% (Ferreira et al., 1996), and based on these findings its contribution to night SWD cannot be large. However, soil water variation is mainly a consequence of both soil evaporation and crop transpiration, to which other not quantified factors participate, like redistribution.

Hence, transpiration also occurs during night. Thus, according to some authors, "nighttime transpiration rates generally vary from $5 \%$ to $15 \%$ of daytime rates, sometimes up to 30\%" (Benyon, 1999; Snyder et al., 2003; Bucci et al., 2004; Daley and Phillips, 2006).
"Incomplete stomatal closure during the night is observed in a diverse range of plant species and can lead to substantial nighttime transpirational water loss" (Caird et al., 2007). Other authors (Kupper et al., 2012) suggest the idea that the nocturnal transpiration, as percentage of the diurnal one, depend not only on the plant species but also on soil fertility and soil $\mathrm{N}$ content and availability.

The other SWD ratio investigated, between 14:00 to 20:00 $\mathrm{h}$ and 08:00 to 14:00 $\mathrm{h}$, is higher than 1 for both irrigated treatments. It ranges between 1.02 and 1.46 in $\mathrm{T} 1$ and between 2.0 and 8.64 in T2 (Table 4), with the general averages of 1.25 and 3.84 , respectively. Rs cannot be the cause of these values, because it varies inversely with the above ratio (Table 2). However, the analysis of air temperature $(\mathrm{T})$ reveals that it could be a favoring factor, being higher in the second part of the daylight (14:0020:00 h) vs. the first part (08:00-14:00 h). The same finding was noted for VPD and U, as shown above, and these two climatic features enhance evapotranspiration, and together with $\mathrm{T}$ exert a prevailing influence on SWD magnitude.

Comparing our data with the results on young sweet cherry reported by Juhász (2012) from a neighbor region, the latter has shown that the main peak in sap flow rate and implicitly in tree water uptake (transpiration) occur daily between 08:00 and 10:00 h, followed by a drop, with a second peak between 14:00 and 16:00 h. After 18:00 $\mathrm{h}$ the sap flow rate decreases to a minimum level till about 02:00 and starts increasing again in the morning. The morning water uptake was $5-10 \%$ greater than in the afternoon, while the average water uptake during the night was $5.6 \%$ of that of daytime. Juhász (2012) has also found out positive relationships between sap flow, on the one hand, and air temperature, solar radiation, vapor pressure deficit and wind speed on the other hand, as in our case. Unlike the above data, our data refer to SWD that mainly consists of both evaporation and transpiration; that is why our SWD determined in the afternoon is higher than in the morning, however in the case of daytime and nighttime SWD the results are consistent with each other.

As shown, SWD is consistently influenced by ${\mathrm{PM}-\mathrm{ET}_{0}}$ and crop evapotranspiration, and thus the SWD values are affected by both daytime and nighttime crop transpiration, as well as by morning and afternoon distribution of the climatic elements studied. This is true not only in the fully irrigated treatment, when water moves easily in a well structured porous soil, but also in the water stressed treatment, when water is retained much stronger in the soil matrix and circulates also as a gaseous phase through the soil pores.

\section{CONCLUSIONS}

The novelty of this paper consists in the presented ratios between the soil water discharges of the different parts of the day on which the study is based. In order to find 
out and compare data under various environmental conditions, daylight soil water discharge (SWD) was studied in two irrigation regime treatments, one of them being fully irrigated-T1 and the other water stressed-T2. Under the semi-arid conditions investigated, during all depletion cycles in $\mathrm{T} 1$ a breaking point was noted in the soil moisture content dynamics, corresponding to a soil water tension of 20-30 kPa range, representing around 65$77 \%$ of the available SMC, but there is no clear evidence that the early water stress occurred in that specific moment for trees; it rather seems to occur gradually in time. Whole day SWD decreases abruptly in the first 1-2 $\mathrm{d}$ from irrigation ceasing $(7-10 \mathrm{~mm})$ when percolation is usually maximum, to $4-6 \mathrm{~mm} \mathrm{~d}^{-1}$, and then the decrease is gentle, 2-3 $\mathrm{mm} \mathrm{d}^{-1}$ after about $1 \mathrm{wk}$.

In the non-stressed treatment, the ratio between light SWD and dark SWD is always $>1$, but t-test is not significant due to high data dispersion; this has been attributed to the effects of Rs, T, VPD, and U on trees, because photosynthesis, transpiration and crop water uptake are higher during daylight $v s$. the dark period of the day (1.87 ratio in this case in T1 and 1.50 in T2). The SWD ratio between 14:00-20:00 $\mathrm{h}$ and 08:00-14:00 $\mathrm{h}$ is higher than 1 for both $\mathrm{T} 1$ and $\mathrm{T} 2$ treatments. This could be attributed more to the T, VPD and $\mathrm{U}$ values that are higher in the second part of the daylight (14:00-20:00 h) vs. the first part (08:00-14:00 h), than to Rs that is lower in the afternoon.

The results emphasize the link between some climate features, crop evapotranspiration and SWC dynamics and could be utilized by fruit growers to improve water management and conservation in semiarid regions with similar environmental conditions. Future research focused on plant transpiration related to soil water content dynamics and climate features are needed to deepen these ecological processes in the case of various fruit tree orchards.

\section{LITERATURE CITED}

Allen, R.G., L. Pereira, D. Raes, and M. Smith. 1998. Crop evapotranspiration. Guidelines for computing crop water requirements. FAO Irrigation and Drainage Paper 56.301 p. FAO, Rome, Italy.

Benyon, R. 1999. Nighttime water use in an irrigated Eucalyptus grandis plantation. Tree Physiology 19:853-859.

Bucci, S.J., F.G. Scholz, G. Goldstein, F.C. Meinzer, J.A. Hinojosa, W.A. Hoffman, and A.C. Franco. 2004. Processes preventing nocturnal equilibration between leaf and soil water potential in tropical savanna woody species. Tree Physiology 24:1119-1127.

Caird, M.A., J.H. Richards, and L.A. Donovan. 2007. Nighttime stomatal conductance and transpiration in $\mathrm{C}_{3}$ and $\mathrm{C}_{4}$ plants. Plant Physiology 143:4-10.

Chalmers, D.J., P.D. Mitchell, and L. Van Heek. 1981. Control of peach tree growth and productivity by regulated water supply, tree density and summer pruning. Journal of the American Society for Horticultural Science 106:307-312.

Correia, M.J., M.L. Rodrigues, M.I. Ferreira, and J.S. Pereira. 1997. Diurnal change in the relationship between stomatal conductance and abscisic acid in the xylem sap of field-grown peach trees. Journal of Experimental Botany 48:1727-1736.
Daley, M.J., and N.G. Phillips. 2006. Interspecific variation in nighttime transpiration and stomatal conductance in a mixed New England deciduous forest. Tree Physiology 26:411-419.

Dry, P.R., B.R. Loveys, H. Duering, and B.G. Botting. 1996. Effects of partial root-zone drying on grapevine vigour, yield composition of fruit and use of water. p. 128-131. In Stockley, C.S., A.N. Sas, R.S. Johnstone, and T.H. Lee (eds.) Proceedings of the $9^{\text {th }}$ Australian Wine Industry Technical Conference, Adelaide, Australia.

Ferreira, M., C. Valancogne, F.A. Daudet, T. Ameglio, C. Arruda Pacheco, and J. Michaelsen. 1996. Evapotranspiration and cropwater relations in a peach orchard. p. 61-68. Evapotranspiration and irrigation scheduling. Proceedings of the International Conference, San Antonio, Texas. 3-6 November. Available at http://www.isa.utl.pt/wateruse/PUBLICATIONS/Ferreira TEXASF21a.pdf (accessed 29 March 2013).

Goldhamer, D.A., M. Viveros, and M. Salinas. 2006. Regulated deficit irrigation in almonds: effects of variations in applied water and stress timing on yield and yield components. Irrigation Science 24:101-114.

Indreias, A. 1997. Arhitectonica sistemului radicular la soiul Springrest altoit pe sase portaltoi. Lucrari stiintifice. p. 203-210. INFCON, Constanţa, Romania.

Iosifescu, M., C. Moineagu, V. Trebici, and E. Ursianu. 1985. Mica enciclopedie de statistica. 612 p. Editura Stiintifica si Enciclopedica, Bucuresti, Romania.

Juhász, A. 2012. Determination of water uptake dynamics of intensive sweet cherry orchard based on sap flow measurements. $\mathrm{PhD}$ thesis. Corvinus University of Budapest, Faculty of Horticultural Sciences. Available at http://phd.lib.uni-corvinus. hu/608/2/Juhasz_Agota_ten.pdf (accessed January 2013).

Kupper, P., G. Rohula, L. Saksing, A. Sellin, K. Lõhmus, I. Ostonen, et al. 2012. Does soil nutrient availability influence night-time water flux of aspen saplings? Environmental and Experimental Botany 82:37-42.

McDonald, E.P., J.E. Erickson, and E.L. Kruger. 2002. Can decreased transpiration limit plant nitrogen acquisition in elevated $\mathrm{CO}_{2}$ ? Functional Plant Biology 29:1115-1120.

Nye, P.H., and P.B. Tinker. 1977. Solute movement in the soil-root system. Blackwell Scientific Publications, Oxford, UK.

Paço, T.A., N. Conceição, and M.I. Ferreira. 2004. Measurements and estimates of peach orchard evapotranspiration in Mediterranean conditions. Acta Horticulturae 664:505-512.

Paltineanu, C., I.F. Mihailescu, I. Seceleanu, C. Dragota, and F. Vasenciuc. 2007. Ariditatea, seceta, evapotranspiratia si cerintele de apa ale culturilor agricole in Romania. 319 p. Editura Ovidius University Press, Constanţa, Romania.

Paltineanu, C., L. Septar, C. Moale, A. Opriţa, and G. Lamureanu. 2011. Peach irrigation under soil water stress in the south-eastern part of Romania. Acta Horticulturae 922:195-202.

Ruiz-Sanchez, M.C., R. Domingo, and J.R. Castel. 2010. Review. Deficit irrigation in fruit trees and vines in Spain. Spanish Journal of Agricultural Research 8(S2):S5-S20.

Snyder, K.A., J.H. Richards, and L.A. Donovan. 2003. Night-time conductance in $\mathrm{C}_{3}$ and $\mathrm{C}_{4}$ species: Do plants lose water at night? Journal of Experimental Botany 54:861-865.

Soil Survey Staff. 1999. Soil taxonomy - A basic system of soil classification for making and interpreting soil surveys. $2^{\text {nd }}$ ed. USDA-SCS. Agricultural Handbook 436. 869 p. Natural Resources Conservation Service, USDA, Washington DC, USA.

Tardieu, F., and W.J. Davies. 1992. Stomatal response to abscisic acid is a function of current plant water status. Plant Physiology 98:540-549.

World Reference Base for Soil Resources. 2006. A framework for international classification, correlation and communication. 145 p. FAO, Rome, Italy. Available at ftp://ftp.fao.org/agl/agll/docs/ wsrr103e.pdf (accessed 29 March 2013). 